\title{
Obediencia sacerdotal como una de las especiales obligaciones de los clérigos en la Iglesia católica
}

\section{Priestly Obedience as One of the Special Duties of Priests in the Catholic Church}

\begin{abstract}
During this year's homily on Holy Thursday Pope Benedict XVI explored the subject of priestly obedience. He drew attention to some European priests' incitement to disobedience which ignored the teaching of the Magisterium of the Church. This article argues for the importance and role of priestly obedience in the Catholic Church. Firstly, it identifies the nature of obedience through a close examination of the documents of the Second Vatican Council. Secondly, it identifies Pope Paul VI teaching on obedience through the magisterium of the Church. Finally, the nature of obedience in the Code of the Canon Law from 1983 onwards as well as practical manifestations of obedience pursuant to the Congregation for the Evangelization of Peoples is discussed.
\end{abstract}

\section{Keywords}

Teaching of the Pope Paul VI, Pastores dabo vobis, submission, priestly obedience.

En nuestro tiempo, entretejido de relativismo y de modelos democráticos, de autonomismos y liberalismos, parece que sea cada vez más incomprensible la promesa de la obediencia sacerdotal. 


\section{The Person and the Challenges \\ 194

"Edúquense especialmente en la obediencia sacerdotal", exhorta el Concilio Vaticano II a los candidatos al sacerdocio. La obediencia es virtud sacerdotal, no sólo porque ha de ser vivida por los sacerdotes, sino en sí misma. Existe, en efecto, una estrecha relación entre obediencia y sacerdocio, porque la principal función del sacerdote es ofrecer el sacrificio, y la obediencia es el sacrificio más grato a Dios.

El papa Benedicto XVI en la Misa Crismal de Jueves Santo en este ańo decía: "Recientemente, un grupo de sacerdotes ha publicado en un país europeo una llamada a la desobediencia, aportando al mismo tiempo ejemplos concretos de cómo se puede expresar esta desobediencia, que debería ignorar incluso decisiones definitivas del Magisterio; por ejemplo, en la cuestión sobre la ordenación de las mujeres, sobre la que el beato Papa Juan Pablo II ha declarado de manera irrevocable que la Iglesia no ha recibido del Seńor ninguna autoridad sobre esto. Pero la desobediencia, żes un camino para renovar la Iglesia? Queremos creer a los autores de esta llamada cuando afirman que les mueve la solicitud por la Iglesia; su convencimiento de que se deba afrontar la lentitud de las instituciones con medios drásticos para abrir caminos nuevos, para volver a poner a la Iglesia a la altura de los tiempos. Pero la desobediencia, żes verdaderamente un camino?"2. Precisamente ese es uno de los motivos principales de escribir este artículo: frente a las críticas de la obediencia, dar a conocer al lector una doctrina católica acerca de la obediencia canónica.

\section{La obediencia sacerdotal como un instrumento para hacer efectiva la comunión jerárquica de la Iglesia en Ios documentos del Concilio Vaticano II}

Antes de caracterizar la obediencia sacerdotal, brevemente, nos ocuparemos de la obediencia de todos los cristianos. La Constitución dogmática sobre la Iglesia: Lumen gentium, afirma: "Los laicos, al igual que todos los fieles cristianos, tienen el derecho de recibir con abundancia de los sagrados Pastores los auxilios de los bienes espirituales de la Iglesia, en particular la palabra de Dios y les sacramentos. Y manifiéstenles sus necesidades y sus deseos con aquella libertad y confianza que conviene a los hijos de Dios"3. Un signo visible de la comunión jerárquica es la sumisión y obediencia al Magisterio de la Iglesia. La mencionada antes Constitución

\footnotetext{
${ }^{1}$ Concilio Vaticano II, Decreto Optatam totius, 9.

${ }^{2}$ Benedicto XVI, Homilía en la Misa Crismal 5.IV.2012, Cittá del Vaticano 2012, p. 2.

${ }^{3}$ Concilio Vaticano II, Constitución Lumen gentium, 37.
} 
dogmática lo recuerda así: "los fieles, por su parte, en materia de fe y costumbres, deben aceptar el juicio de su obispo, dado en nombre de Cristo, y deben adherirse a él con religioso respeto. Este obsequio religioso de la voluntad y del entendimiento de modo particular ha de ser prestado al magisterio auténtico del Romano Pontífice aun cuando no hable ex cathedra; de tal manera que se reconozca con reverencia su magisterio supremo y con sinceridad se preste adhesión al parecer expresado por él, según su manifiesta mente y voluntad, que se colige principalmente ya sea por la índole de los documentos, ya sea por la frecuente proposición de la misma doctrina, ya sea por la forma de decirlo"4. Lumen gentium, después de afirmar el deber de obediencia de los laicos, recomienda vivamente que "los sagrados Pastores reconozcan y promuevan la dignidad y responsabilidad de los laicos en la Iglesia. Recurran gustosamente a su prudente consejo, encomiéndenles con confianza cargos en servicio de la Iglesia y denles libertad y oportunidad para actuar; más aún, anímenles incluso a emprender obras por propia iniciativa. Consideren atentamente ante Cristo, con paterno amor, las iniciativas, los ruegos y los deseos provenientes de los laicos. En cuanto a la justa libertad que a todos corresponde en la sociedad civil, los Pastores la acatarán respetuosamente"5. Estos límites no significan independencia del fiel de la autoridad de la Iglesia en el ejercicio de sus actividades temporales, ni en el marco de su vida privada. Como afirma el analizado documento Lumen gentium en el n. 36: "Conforme lo exige la misma economía de la salvación, los fieles aprendan a distinguir con cuidado los derechos y deberes que les conciernen por su pertenencia a la Iglesia y los que les competen en cuanto miembros de la sociedad humana. Esfuércense en conciliarlos entre sí, teniendo presente que en cualquier asunto temporal deben guiarse por la conciencia cristiana, dado que ninguna actividad humana, ni siquiera en el dominio temporal, puede substraerse al imperio de Dios".

Tomás Rincón-Pérez reconoce que la autonomía de las realidades temporales, el pluralismo político, las múltiples opciones, aún dentro de la justicia, a que da lugar la dinámica de los diversos grupos sociales, son factores que dificultan en la práctica una delimitación clara del objeto sobre el que puede y debe iniciar la voz autorizada de la Iglesia. Es claro que dicha dificultad no debe desembocar ni en una renuncia al derecho, ni en una meditada y prudente decisión, a fin de no convertir en clericalismo de nuevo cuńo lo que debiera ser un legítimo pronunciamiento profético ${ }^{6}$.

\footnotetext{
${ }^{4}$ Ibídem, 25.
}

${ }^{5}$ Ibídem, 37.

${ }^{6}$ Cfr. T. Rincón-Pérez, La Iglesia y el orden temporal, en: J. M. Gonzáles del Valle, T. RincónPérez, Iglesia-Estado y conciencia cristiana, Madrid 1971, p. 80. 
Después de haber visto la obediencia como algo necesario para todos los cristianos, la obediencia de los sacerdotes es un instrumento necesario para hacer efectiva la comunión Jerárquica de la Iglesia. El Decreto conciliar Presbyterorum ordinis lo expresa en estos términos: "el ministerio sacerdotal es el ministerio de la misma Iglesia, no puede efectuarse más que en la comunión jerárquica de todo el cuerpo. La caridad pastoral urge, pues, a los presbíteros que, actuando en esta comunión, consagren su voluntad propia por la obediencia al servicio de Dios y de los hermanos"?.

En el rito de la Ordenación presbiteral, el nuevo sacerdote diocesano promete obediencia a su obispo, pues es éste su ordinario, bajo cuya jurisdicción queda incardinado. El abad Columba Marmion recuerda, que el fin de esta promesa es el servicio del sacerdote a la diócesis en la realización de su ministerio. Dice así: "Después de la ordenación, habéis prometido la obediencia a vuestro obispo; se trata, por tanto, de un juramento solemne, emitido en las manos del pontífice en la hora más delicada de vuestra vida. Con esto, os habéis comprometido, en la presencia de Dios y ante el altar sobre el cual, junto al prelado consagrante, acabáis de ofrecer, por primera vez, el Santo Sacrificio. El compromiso, que acabáis de hacer, no os vincula ciertamente del mismo modo que a los religiosos, cuando emiten un voto de obediencia perpetua a un superior. La Iglesia considera tal promesa un medio de santificación libremente elegido, para que, con una completa renuncia, toda su persona y toda su actividad sean siempre consagrados a Dios. Vuestra promesa de obediencia tiene otro carácter: ante todo, la Iglesia la exige de vosotros para el bien común de la diócesis"8.

Los presbíteros están unidos a los obispos y participan en el ministerio episcopal: "Los presbíteros, por su parte, considerando la plenitud del Sacramento del Orden de que están investidos los obispos, acaten en ellos la autoridad de Cristo, supremo Pastor. Estén, pues, unidos a su obispo con sincera caridad y obediencia. Esta obediencia sacerdotal, ungida de espíritu de cooperación, se funda especialmente en la participación misma del ministerio episcopal que se confiere a los presbíteros por el Sacramento del Orden y por la misión canónica".

La obediencia en la vida del sacerdote es imprescindible para poder desempeńar su propio ministerio. El Decreto Presbyterorum ordinis así inicia la descripción de la obediencia sacerdotal: "disposición de alma por la que están siempre preparados a buscar, no su voluntad, sino la voluntad de quien los envió. Porque

\footnotetext{
${ }^{7}$ Concilio Vaticano II, Decreto Presbyterorum ordinis, 15.

${ }^{8}$ D. Columba Marmion, Cristo ideal del sacerdote, Milano 1959, p. 144-145 (citado por M. Areitio, Obediencia y libertad en la vida consagrada, Pamplona 2004, p. 109).

${ }^{9}$ Presbyterorum ordinis, 7.
} 
la obra divina, para cuya realización los tomó el Espíritu Santo, trasciende todas las fuerzas humanas y la sabiduría de los hombres, pues «Dios eligió los débiles del mundo para confundir a los fuertes» (1 Cor., 1, 27). Conociendo, pues, su propia debilidad, el verdadero ministro de Cristo trabaja con humildad, buscando lo que es grato a Dios, y como encadenado por el Espíritu, es llevado en todo por la voluntad de quien desea que todos los hombres se salven; voluntad que puede descubrir y cumplir en los quehaceres diarios, sirviendo humildemente a todos los que Dios le ha confiado, en el ministerio que se le ha entregado y en los múltiples acontecimientos de su vida" ${ }^{10}$. Más adelante el documento conciliar describe el modo cómo han de obedecer los sacerdotes y el objetivo propio de dicha obediencia: "actuando en esta comunión, consagren su voluntad propia por la obediencia al servicio de Dios y de los hermanos, recibiendo con espíritu de fe y cumpliendo los preceptos y recomendaciones emanadas del Sumo Pontífice, del propio obispo y de otros superiores; gastándose y agotándose de buena gana en cualquier servicio que se les haya confiado, por humilde y pobre que sea. De esta forma guardan y reafirman la necesaria unidad con sus hermanos en el ministerio, y sobre todo con los que el Seńor constituyó en rectores visibles de su Iglesia, y obran para la edificación del Cuerpo de Cristo, que crece «por todos los ligamentos que lo nutren» (cfr. Ef 4, 11-16)"'11.

El presbítero tiene también ciertas obligaciones en sus relaciones con el obispo. El ámbito de todas estas obligaciones es el ministerio sacerdotal: "Esta obediencia, que conduce a la libertad más madura de los hijos de Dios, exige por su naturaleza que, mientras movidos por la caridad, los presbíteros, en el cumplimiento de su cargo, investigan prudentemente nuevos caminos para el mayor bien de la Iglesia, propongan confiadamente sus proyectos y expongan instantemente las necesidades del rebańo a ellos confiado, dispuestos siempre a acatar el juicio de quienes desempeńan la función principal en el régimen de la Iglesia de Dios. Los presbíteros, con esta humildad y esta obediencia responsable y voluntaria, se asemejan a Cristo, sintiendo en sí lo que en Cristo Jesús, que «se anonadó a sí mismo, tomando la condición de esclavo, hecho obediente hasta la muerte» (Fil. 2, 7-9)"12.

\footnotetext{
${ }^{10}$ Ibídem, 15.

${ }^{11}$ Ibídem.

${ }^{12}$ Ibídem.
} 


\section{Sentido de la obediencia en el Magisterio de Pablo VI}

La obediencia y la autoridad en la Iglesia fueron unos de los temas más constantes en el Magisterio del papa Pablo VI. Su catequesis va a iluminar la doctrina de la obediencia sacerdotal recogida en el Código de Juan Pablo II de 1983.

En el discurso en la Audiencia general del 5 de octubre de 1966 el papa presenta su preocupación por la situación de la Iglesia y dice así: "Qué es lo que más necesita hoy día la Iglesia? Os daremos una respuesta que vosotros, que sois buenos, fieles y fervorosos, podéis comprender y aceptar: la Iglesia necesita obediencia. Sí, hijos e hijas que amáis a la Iglesia, obediencia. Y más que una obediencia externa y pasiva, una obediencia interna y espontánea"13. En el mismo discurso, frente a los que entienden que la noción de obediencia es ajena al espíritu del Concilio Vaticano II, les aclara: "żInterpreta de verdad la obediencia del espíritu del Concilio? żNo ha hablado el Concilio de los derechos de la personalidad, de la conciencia y de la libertad? Sí, ha hablado de estos temas, pero no ha guardado silencio con respeto a la obediencia (...) queremos simplemente recordar que estas prerrogativas del alma cristiana no se ven menoscabadas, ante bien, quedan tuteladas y moderadas por la obediencia vigente en el cuerpo de la Iglesia"14.

Una de las preocupaciones más constantes en el Magisterio de Pablo VI, es la de presentar la autoridad como un servicio en todos los ámbitos de la vida de la Iglesia. El papa, en la Audiencia general del 12 de marzo de 1969, describía la mentalidad del hombre moderno: "El hombre moderno no quiere sentirse servidor de autoridad ni de ley alguna, su instinto de libertad, extraordinariamente desarrollada, le inclina a hacer su capricho, al desenfreno y hasta a la anarquía. En el mismo seno de la Iglesia esta idea de servicio, y por tanto la idea de obediencia, encuentra no poca contestación, ni siquiera los seminarios constituyen una excepción. La autoridad en la Iglesia es servicio de caridad y ejercicio de amor (cfr. Gal 5, 13), y el amor es fuerza de Dios que capacita para cosas muy altas, sobrehumanas, si es preciso"15.

Teniendo en cuenta la mentalidad del hombre moderno, Pablo VI empieza por desarrollar cómo la obediencia es ley constitucional de la Iglesia y qué alcance tiene

${ }^{13}$ Pablo VI, Audiencia general, La obediencia sigue en pie, 5.X.1966, en: Insegnamenti di Paolo VI, vol. IV, 1966, Cittá del Vaticano 1967, p. 863.

${ }^{14}$ Ibídem.

${ }^{15}$ Pablo VI, Audiencia general, El servicio como estilo pastoral, 12.III.1969, en: Pablo VI, Enseñanzas al Pueblo de Dios, vol. 1, 1969, Cittá del Vaticano 1970, p. 33-34. 
la autoridad dentro de ella: "Son innumerables los textos que podríamos acudir para probar que la obediencia es ley constitucional de la Iglesia. (...) Porque en la Iglesia - como en toda la sociedad - la autoridad existe y resulta indispensable, pero con esta particularidad: que en la Iglesia la autoridad no surge de la base ni del número, sino que proviene - como todos saben - de la institución originaria e inmutable de Cristo. Y esta autoridad que posee la Iglesia tiene por objeto no sólo los actos externos de quienes se someten a sus directrices, sino incluso - en cierta medida - algunos actos internos de no poca importancia, como la regla de la fe; por ejemplo: nos adherimos libremente a la fe, pero después la norma de la misma fe resulta vinculante. Y es la Iglesia quien se constituye en garantía y tutela de esta norma"16.

María Areitio observa, que el papa Pablo VI no deja de poner de manifiesto que la obediencia no es una mera sumisión pasiva, sino un compromiso consciente que pone en juego toda la persona humana, todas sus capacidades y facultades, para que el hombre actúe con libertad y responsabilidad, y busque así el bien, el amor y la justicia ${ }^{17}$.

En la Audiencia general 24 de julio de 1974, Pablo VI deja claro que se debe recuperar un ejercicio positivo de la obediencia. El papa afirma que: "La autoridad, no dominadora ni egoísta, sino educadora y moderadora, puesta al servicio de cada una de las personas y más particularmente de cada ordenamiento colectivo, es necesaria; y lo es también en cuanto delegada de la Dios y elevada al estilo y la función pastoral, en la Iglesia de Dios, por decisión institucional de Cristo y por contar con la prueba de la experiencia de los santos y de la historia. Correlativa con la autoridad es la obediencia, que no es mera pasividad ni aquiescencia servil por interés o por miedo, sino expresión de unidad, de fidelidad y de caridad, en la articulación del Cuerpo místico y social de Cristo, que es su Iglesia. Sobreabundan a este respecto los textos de la Escritura, las expresiones y los ejemplos de los santos y las pruebas constantemente repetidas de los protagonistas del reino de Dios en la historia, que tiene en la obediencia humilde y generosa de sus promotores la argamasa fuerte para su construcción y la contraseńa elocuente de su caridad vivificante"18.

\footnotetext{
${ }^{16}$ Pablo VI, Audiencia general, La obediencia eclesial, fuente de libertad, 28.I.1970, en: Pablo VI, Enseñanzas al Pueblo de Dios, vol. 2, 1970, Cittá del Vaticano 1971, p. 18.

${ }^{17}$ Cfr. M. Areitio, Obediencia y libertad ... cit., p. 18.

${ }^{18}$ Audiencia general, Libertad y obediencia, 24.VII.1974, en: Pablo VI, Enseñanzas al Pueblo de Dios, vol. 6, 1974, Cittá del Vaticano 1975, p. 99-100.
} 


\section{La obediencia de los clérigos en el Código de Juan Pablo II}

En esta parte vamos a analizar primero el deber de obediencia que contiene el c. 273 del Código de Derecho Canónico, y luego los ámbitos de dicha obediencia. Por fin analizaremos en qué consiste la autonomía del los clérigos en el deber de la obediencia.

\subsection{El deber de la obediencia}

En el c. 273 del Código de Derecho Canónico de 1983 leemos: "Los clérigos tienen especial obligación de mostrar respeto y obediencia al Sumo Pontífice y a su ordinario propio". Esta obligación es fruto no sólo del sacramento del orden que han recibido, sino de la consecuente incardinación y misión canónica, que recibe todo presbítero. Jorge de Otaduy comentando este canon dice, que las actitudes de respeto y obediencia de los clérigos hacia las autoridades eclesiales, mencionadas en este canon, no responden simplemente a manifestaciones del ejercicio del poder de jurisdicción ni a meras motivaciones de índole pastoral, sino que expresan aspectos esenciales de la naturaleza y de la misión de los presbíteros ${ }^{19}$.

El Directorio para el misterio y la vida de los presbíteros ${ }^{20}$ advierte que: "no son transferibles automáticamente a la Iglesia la mentalidad y la praxis que se dan en algunas corrientes culturales sociopolíticas de nuestro tiempo. El así llamado democraticismo constituye una tentación gravísima, pues lleva a no conocer la autoridad y la gracia capital de Cristo y a desnaturalizar la Iglesia, como si ésta no fuese más que una sociedad humana. Una concepción así acaba con la misma constitución jerárquica, tal como ha sido querida por su Divino Fundador, como siempre ha enseńado claramente el Magisterio y como la misma Iglesia ha vivido interrumpidamente" 21 .

\subsection{Los ámbitos de la obediencia}

El c. $274 \S 2$ especifica que, una de las consecuencias de la debida obediencia de los clérigos a su ordinario, es el deber de aceptar el oficio o tarea que éste

\footnotetext{
${ }^{19}$ Cfr. J. de Otaduy, Comentario al c. 273, en: A. Marzoa, J. Miras, R. Rodríguez-Ocaña (ed.), Comentario Exegético al Código de Derecho Canónico, vol. II/1, Pamplona 1997, p. 319. Cfr. J. Krukowski, Komentarz do kan. 273, en: J. Dyduch, W. Góralski, E. Górecki, J. Krukowski, M. Sitarz (ed.), Komentarz do Kodeksu Prawa Kanonicznego, vol. II/1 Lud Boży, Poznań 2005, p. 93-94.

${ }^{20}$ Congregación para el Clero, Directorio para el misterio y la vida de los presbiteros, 31.I.1994.

${ }^{21}$ Ibídem, 17.
} 
les encomiende: "A no ser que estén excusados por un impedimento legítimo, los clérigos deben aceptar y desempeńar fielmente la tarea que les encomiende su ordinario". El mencionado canon tiene también su base en la institución de la incardinación. Precisamente, uno de sus efectos es que el presbítero queda vinculado al servicio ministerial de una determinada Iglesia particular, o de la estructura pastoral a la que se incorpora. Por este motivo su obediencia se debe concretar en una general disponibilidad a asumir la tarea que le confíe su ordinario ${ }^{22}$.

El ámbito de la obediencia sacerdotal llega más lejos, obviamente, de lo que seńala el c. 274. La incardinación vincula al presbítero no sólo con el obispo, sino con los restantes componentes de esta porción del Pueblo de Dios en que se concreta su ministerio: presbiterio y pueblo cristiano. El papa Juan Pablo II seńala las características de la obediencia sacerdotal: "Se trata de la obediencia, que, en el caso de la vida espiritual del sacerdote, presenta algunas características peculiares. Es, ante todo, una obediencia «apostólica», en cuanto que reconoce, ama y sirve a la Iglesia en su estructura jerárquica. En verdad no se da ministerio sacerdotal sino en la comunión con el Sumo Pontífice y con el Colegio episcopal, particularmente con el propio Obispo diocesano, hacia los que debe observarse la «obediencia y respeto» filial, prometidos en el rito de la ordenación. Esta sumisión a cuantos están revestidos de la autoridad eclesial no tiene nada de humillante, sino que nace de la libertad responsable del presbítero, que acoge no sólo las exigencias de una vida eclesial orgánica y organizada, sino también aquella gracia de discernimiento y de responsabilidad en las decisiones eclesiales, que Jesús ha garantizado a sus apóstoles y a sus sucesores, para que sea guardado fielmente el misterio de la Iglesia, y para que el conjunto de la comunidad cristiana sea servida en su camino unitario hacia la salvación”"23. La obediencia sacerdotal tiene también - según el papa polaco - un carácter pastoral: "se vive en un clima de constante disponibilidad a dejarse absorber, y casi «devorar», por

${ }^{22}$ M. Areitio, Obediencia y libertad ... cit., p. 210. Cfr. J Krukowski, Komentarz do kan. 274, en: J. Dyduch, W. Góralski, E. Górecki, J. Krukowski, M. Sitarz (ed.), Komentarz ... cit., p. 94-95. Los ámbitos de obediencia de los clérigos están relacionados con todo lo que se refiere al ejercicio del ministerio sagrado y con todos los campos que tengan relación directa e inmediata con el ministerio. En este tema consulte: T. Rincón-Pérez, El orden de los clérigos o ministros sagrados, Pamplona 2009, p. 297-322; R. Kantor, Dążenie do doskonałości - podstawowym wymogiem kanonicznym kapłanów, „Teologia praktyczna” 11 (2010), p. 95-108; R. Kantor, Ars vitae kaptana. Kanoniczne uwarunkowania prostoty życia duchownych, en: A. Kokoszka, J. Siewiora (ed.), Kapłan we wspólnocie wierzacych. Różne aspekty formacji i postugi kapłańskiej, Tarnów 2010, p. 81-103.

${ }^{23}$ Juan Pablo II, Exhortación apostólica postsinodal Pastores dabo vobis, 28. 
las necesidades y exigencias de la grey. Es verdad que estas exigencias han de tener una justa racionalidad, y a veces han de ser seleccionadas y controladas; pero es innegable que la vida del presbítero está ocupada, de manera total, por el hambre del evangelio, de la fe, la esperanza y el amor de Dios y de su misterio, que de modo más o menos consciente está presente en el Pueblo de Dios que le ha sido confiado" 24 .

\subsection{Autonomía de los clérigos}

La obediencia canónica no entraña una actitud de mera pasividad, sino que se configura como responsabilidad en el ministerio. Teniendo en cuenta todo lo expuesto en los cánones 283, 285, 286, en otros ámbitos de la vida los presbíteros gozan de un amplio espacio de autonomía. Así p. ej. el presbítero tiene el deber de continuar su formación después de la ordenación para poder cumplir con su deber y obtener una mejor formación humana, espiritual, intelectual y pastoral. Tomás Rincón-Pérez subraya, que, en este caso, se trata de un derecho de libertad en el sentido de que nada debe impedirle que, junto a los establecidos por el obispo, el sacerdote pueda elegir libremente un determinado cauce o medio para su formación, con la única condición de que ese medio no ponga en peligro la comunión eclesial, sino que sea un reflejo de la enriquecedora pluralidad eclesial, que también se hace presente en el presbiterio ${ }^{25}$.

Dentro de esta pluralidad eclesial, el c. $278 \S 1$ reconoce a los clérigos seculares el derecho de asociación. Se trata de asociaciones cuyos fines estén de acuerdo con el estado clerical. Pero podría haberse entendido como un límite uniformador de toda la vida espiritual del sacerdote, cerrando el paso a cualquier asociación de clérigos que tuviera como fin una espiritualidad propia y complementaria de la espiritualidad fundamental radicada en el sacramento del orden ${ }^{26}$. El $\S 3$ del mismo canon especifica: "Absténganse los clérigos de constituir o participar en asociaciones, cuya finalidad o actuación sean incompatibles con las obligaciones propias del estado clerical o puedan ser obstáculo para el cumplimiento diligente de la tarea que les ha sido encomendada por la autoridad eclesiástica competente". No se trata pues de negar a los clérigos el derecho de asociación, sino de indicarles que el uso del mismo debe ser compatible con su propia condición jurídica.

\footnotetext{
${ }^{24}$ Ibídem.

${ }^{25}$ Cfr. T. Rincón-Pérez, La formación permanente de los sacerdotes, en: T. Rincón-Pérez (ed.), Relaciones de justicia y ámbitos de libertad en la Iglesia. Nuevos perfiles de la ley canónica, Pamplona 1997, p. 304.

${ }^{26}$ Cfr. T. Rincón-Pérez, El orden de los clérigos ... cit., p. 331.
} 
En la administración de sus bienes, el c. $282 \S 2$ reconoce a los presbíteros el derecho a decidir libremente acerca de la administración de los propios recursos económicos, es decir, deja a su libre decisión el determinar qué bienes propios ha de considerar sobrantes y con qué entidades eclesiales o benéficas quiere colaborar económicamente mediante sus donativos ${ }^{27}$.

El obispo no tiene ningún control sobre la vida privada de sus sacerdotes, quienes tienen derecho a organizarla según consideren más oportuno y conveniente, siempre y cuando en sus decisiones y prácticas de su modus vivendi no contradigan el estado clerical que les es propio $^{28}$.

\section{Manifestaciones concretas de la obediencia sacerdotal seńaladas por la Congregación para la Evangelización de Ios Pueblos}

La obediencia de los sacerdotes debe manifestarse, hoy, de manera especial, en lo siguiente:

- La fidelidad al magisterio: ésta se base en la identidad cristiana y sacerdotal, y se expresa concretamente en una actitud de obediencia al magisterio del Romano Pontífice y de los obispos, de los cuales los sacerdotes no deberán apartarse para seguir teorías que no han sido aprobadas, o convicciones personales; esta fidelidad es indispensable para que sean auténticos y para que puedan presentar una enseńanza conforme a la verdad revelada; los pastores deben guiar a su rebańo, alimentándolo con la sana doctrina ${ }^{29}$;

- La aceptación de los cargos: la fidelidad de los sacerdotes a su tarea de evangelizadores y pastores se manifiesta, ante todo, en la fidelidad con que aceptan y realizan la misión que les ha sido confiada por el obispo. En este campo, se necesita un espíritu de fe, y un sentido práctico de la obediencia, con toda disponibilidad, evitando pedir con demasiada insistencia que se les asignen ciertos cargos o ciertas parroquias, y rechazar lo que manda el obispo. Cuando se trata de nombramientos, los sacerdotes deben permanecer con actitud abierta hacia su obispo, expresándole, en un diálogo franco y sincero, sus ideas; pero, cuando ya está tomada la decisión, deben aceptarla con alegría, sin ulteriores objeciones. Aunque a veces se consideren poco idóneos para desempeńar un

\footnotetext{
${ }^{27}$ Cfr. R. Kantor, Odpowiednie wynagrodzenie duchownych w Kodeksie Prawa Kanonicznego z 1983 r. Analiza kan. 281 § 1, „Prawo Kanoniczne” 54 (2011), n. 3-4, p. 191-222.

${ }^{28}$ Cfr. R. Kantor, Ars vitae kapłana ... cit., p. 81-103.

${ }^{29}$ Cfr. Congregación para la Evangelización de los Pueblos, El sacerdote, espiritualidad y misión. Guía Pastoral para los Sacerdotes Diocesanos de las Iglesias que dependen de la Congregación para la Evangelización de los Pueblos (1.10.1989), 27.
} 


\section{The Person and the Challenges \\ 204

cargo que les sea confiado en nombre de la obediencia, no deben olvidar que una característica peculiar de los sacerdotes diocesanos, como colaboradores del obispo, es comprometerse incondicionalmente para que se solucionen todas las necesidades de la diócesis. Cuando llegue el momento de retirarse, los sacerdotes deben presentar su dimisión al obispo ${ }^{30}$;

- Observancia de las exigencias y normas relacionadas con el cargo: el servicio pastoral en una comunidad cristiana, especialmente si se trata de una parroquia, exige que los presbíteros sean ordenados y fieles en el cumplimiento de sus obligaciones, así como en su comportamiento. "Esto, en primer lugar, en lo referente a las intenciones de las Misas: la Iglesia ha establecido nuevas normas en el nuevo Código a las cuales los sacerdotes han de adherirse con toda atención. Los sacerdotes deben evitar la más pequeńa apariencia de interés económico, y no deben dejar de celebrar, por falta de estipendios, especialmente cuando se trata de los más pobres. Obsérvense además, las normas generales y diocesanas relacionadas con las ofrendas de las binacionales y la Misa por el pueblo. Todo sacerdote anote las Misas que ha recibido, la fecha de la celebración, la intención indicada por el donante, los encargos ya satisfechos y las eventuales transmisiones de intenciones a otros celebrantes. En las parroquias se ha de tener un libro especial para las Misas. Los libros parroquiales, a saber, los registros de bautismos, de matrimonios y de difuntos, y otros prescritos por la Conferencia Episcopal o por el obispo, son importantes para un correcto ejercicio de los derechos y deberes de los fieles. El párroco tiene la obligación de que estén redactados con atención y bien conservados. Además en toda parroquia, ha de haber un archivo ordenado y puesto al día, donde se guarden los libros parroquiales, juntamente con las cartas del obispo y otros documentos importantes. Los sacerdotes han de vestir el traje eclesiástico, según las normas dadas por la Conferencia Episcopal y las costumbres legítimas del lugar. No descuiden con ligereza ese signo de su estado, que llega a ser para ellos una salvaguardia, y un testimonio para los fieles. La residencia es, para los pastores, una obligación que está vinculada estrechamente a su oficio. Sin embargo, conforme a las directrices del obispo, los sacerdotes tienen derecho y necesidad de un suficiente tiempo de vacaciones cada ańo, que les ha de servir como descanso físico y espiritual. Han de concederse, una breve interrupción, posiblemente semanal, en el trabajo, que les servirá también para ponerse al día con lecturas útiles. Sin embargo, antes de alejarse de la parroquia por largo tiempo, deberán, ponerse de acuerdo con el obispo y buscar un sustituto para el cuidado pastoral" ${ }^{\prime 1}$.

\footnotetext{
${ }^{30}$ Cfr. Ibídem.

${ }^{31}$ Ibídem.
} 


\section{Conclusiones}

La obediencia, asumida desde el espíritu cristiano, ha de entenderse ante todo como un valor, no como una carga. En su sentido más profundo nos remite a nuestra propia condición de seguidores de Cristo, el que "se hizo obediente hasta la muerte, y una muerte de cruz" (Flp 2,8). Considerarla a partir de esta dimensión permite a nivel antropológico descubrirla no como algo opuesto a la libertad, sino como una posibilidad de ejercer la propia libertad personal.

El papa Benedicto XVI terminando su homilía del Jueves Santo de este ańo decía: "żAcaso Cristo no ha corregido las tradiciones humanas que amenazaban con sofocar la palabra y la voluntad de Dios? Sí, lo ha hecho para despertar nuevamente la obediencia a la verdadera voluntad de Dios, a su palabra siempre válida. A él le preocupaba precisamente la verdadera obediencia, frente al arbitrio del hombre. Y no lo olvidemos: Él era el Hijo, con la autoridad y la responsabilidad singular de desvelar la auténtica voluntad de Dios, para abrir de ese modo el camino de la Palabra de Dios al mundo de los gentiles. Y, en fin, ha concretizado su mandato con la propia obediencia y humildad hasta la cruz, haciendo así creíble su misión. No mi voluntad, sino la tuya: ésta es la palabra que revela al Hijo, su humildad y a la vez su divinidad, y nos indica el camino" ${ }^{32}$.

La obediencia, en cuanto aceptación e identificación con la voluntad de Dios, es condición necesaria para el seguimiento de Cristo. "La obediencia es solamente una de las formas que configuran la relación del sacerdote con su obispo. No es, por tanto, la única ni siquiera la más importante de esas relaciones. Por eso, sólo se puede lograr una comprensión más completa de la obediencia del sacerdote secular si se la sitúa en el conjunto de las respectivas misiones que presbíteros y obispos tienen en la Iglesia" ${ }^{3}$.

\section{Bibliography}

Areitio M., Obediencia y libertad en la vida consagrada, Pamplona 2004.

Benedicto XVI, Homilía en la Misa Crismal 5.IV.2012, Cittá del Vaticano 2012. Código de Derecho Canónico de 1983.

${ }^{32}$ Benedicto XVI, Homilia en la Misa Crismal 5.IV.2012, Cittá del Vaticano 2012, p. 2.

${ }^{33}$ C. Izquierdo, Notas para la comprensión de la obediencia del sacerdote diocesano, en: La formación de los sacerdotes en las circunstancias actuales: XI Simposio Internacional de Teología de la Universidad de Navarra, edición dirigida por L. F. Mateo-Seco, E. de La Lama, R. Rodríguez-Ocaña, P. O'Callaghan y J. M. Zumaquero, Servicio de Publicaciones de la Universidad de Navarra, Pamplona 1990, p. 680. 
Concilio Vaticano II, Constitución Lumen gentium.

Concilio Vaticano II, Decreto Presbyterorum ordinis.

Izquierdo C., Notas para la comprensión de la obediencia del sacerdote diocesano, en: La formación de los sacerdotes en las circunstancias actuales: XI Simposio Internacional de Teología de la Universidad de Navarra, edición dirigida por L. F. Mateo-Seco, E. de La Lama, R. Rodríguez-Ocaña, P. O’Callaghan y J. M. Zumaquero, Servicio de Publicaciones de la Universidad de Navarra, Pamplona 1990, p. 679-689.

Juan Pablo II, Exhortación Apostólica Pastores dabo vobis.

Kantor R., Ars vitae kapłana. Kanoniczne uwarunkowania prostoty życia duchownych, en: A. Kokoszka, J. Siewiora (ed.), Kapłan we wspólnocie wierzacych. Różne aspekty formacji i postugi kapłańskiej, Tarnów 2010, p. 81-103.

Kantor R., Dążenie do doskonałości - podstawowym wymogiem kanonicznym kapłanów, „Teologia praktyczna” 11 (2010), p. 95-108.

Krukowski J., Komentarz do kan. 273, en: J. Dyduch, W. Góralski, E. Górecki, J. Krukowski, M. Sitarz (ed.), Komentarz do Kodeksu Prawa Kanonicznego, vol. II/1 Lud Boży, Poznań 2005, p. 93-94.

Otaduy J., de, Comentario al c. 273, en: A. Marzoa, J. Miras, R. Rodríguez-Ocaña (ed.), Comentario Exegético al Código de Derecho Canónico, vol. II/1, Pamplona 1997, p. 318-321.

Rincón-Pérez T., El orden de los clérigos o ministros sagrados, Pamplona 2009. 